\title{
RESEARCH
}

\section{Relative value of multiple plasma biomarkers as risk factors for coronary artery disease and death in an angiography cohort}

\author{
Kenny W.J. Lee, John S. Hill, Keith R. Walley, Jiri J. Frohlich
}

$\infty$

See related article page 479

\section{ABSTRACT}

Background: Although elevated levels of C-reactive protein (CRP), interleukin (IL)-6, serum amyloid A protein (SAA) and total homocysteine (tHcy) have been associated with the increased likelihood of cardiovascular events, the relative or combined utility of these biomarkers in predicting atherosclerosis and death in an angiography cohort is unknown.

Methods: A cohort of 1117 consecutive patients (797 men and 320 women), referred to 2 Vancouver teaching hospitals for selective coronary angiography, was recruited between 1993 and 1995. Angiography results were obtained for 1019 patients. In 2004 we determined that of 1050 patients who could be traced, 231 had died, 95 of CAD-related causes. We compared the relative utility of baseline measurements of CRP, IL-6, SAA and tHcy as well as of lipids for predicting angiographic CAD and all-cause and CADrelated death.

Results: The risk of death increased across quartiles for CRP, IL-6, SAA and tHcy. When comparing the highest and lowest quartiles, the greatest hazard ratios were associated with IL-6 $(2.57,95 \%$ confidence interval $[\mathrm{CI}] 1.62-4.09)$ and tHcy $(2.36,95 \% \mathrm{Cl} 1.53-3 \cdot 65)$. A Cox regression model containing all plasma biomarkers and traditional risk factors indicated that age, angiographic CAD and baseline plasma levels of IL- 6 and tHcy remained independent predictors of CAD-related death, whereas age, sex, smoking, diabetes and apolipoprotein $B$ levels were independent predictors of angiographic CAD. Kaplan-Meier survival curves indicated a utility in combining measures of CRP, SAA, IL- 6 and tHcy for predicting risk of all-cause and CADrelated death.

Interpretation: A comparison of elevated levels of CRP, IL-6, SAA and tHcy with traditional CAD risk factors indicated that IL- 6 and tHcy were the strongest independent biomarkers for CAD-related death. Elevated levels of multiple biomarkers were associated with an increasing rate of all-cause and CAD-related death.

CMAJ 2006;174(4):46I-6
$O$ everal plasma biomarkers have been investigated to determine their utility as tools for predicting risk of cardiovascular disease. Elevated levels of C-reactive protein (CRP) have been shown to be a consistent predictor of cardiovascular events in both healthy and diseased populations. ${ }^{1,2}$ However, the results of a recent report from the Reykjavik prospective study indicated that elevated CRP levels were only a moderate predictor of risk compared with established risk factors such as total cholesterol levels and cigarette smoking. ${ }^{3}$ Although interleukin (IL)- 6 is known to induce hepatic synthesis of CRP, there is evidence that elevated IL- 6 and CRP plasma levels are independently related to several cardiovascular risk factors. ${ }^{4}$ Like CRP and IL-6, serum amyloid A protein (SAA) is an acute-phase reactant that has been associated with coronary artery disease $(\mathrm{CAD})^{5-8}$ and is independent of other atherosclerotic risk factors for predicting 3-year risk of major cardiovascular events. ${ }^{9}$ High plasma levels of total homocysteine (tHcy) have been associated with CAD-related death, ${ }^{10,11}$ although the results of meta-analyses have indicated that tHcy is only a modest independent predictor of CAD..$^{12,13}$

There is little data examining the comparative and combined utility of multiple plasma biomarkers for predicting long-term risk of CAD-related death. Since individual biomarkers have been shown to have independent biologic effects, it has been suggested that multiple measures could have additive value in cardiovascular risk assessment. ${ }^{14}$ However, the relative utility of measuring multiple plasma biomarkers to predict risk of angiographic $\mathrm{CAD}$ and $\mathrm{CAD}$-related death remains unclear. Therefore, we compared 4 common plasma biomarkers of CAD, specifically CRP, IL-6, SAA and tHcy, with traditional cardiovascular disease risk factors to assess their relative and cumulative value in predicting all-cause and CAD-related death.

\section{Methods}

A cohort of III7 patients (797 men and 320 women) was recruited from a population of consecutive subjects referred for selective coronary angiography from 2 Vancouver teaching hospitals between 1993 and 1995 . We have reported the genetic and biochemical analyses of this cohort previously. ${ }^{15-17}$ Most ( $87 \%$ ) of the patients in the cohort were white. All signed 
an informed consent form; this research was approved by the Research Ethics Board of St. Paul's Hospital, Vancouver.

At the time of angiography, a 2-page questionnaire regarding clinical and lifestyle variables was administered to every patient by a nurse or attending cardiologist. Information was obtained on ethnicity, smoking status (ever, current and never) and alcohol consumption (never, $\mathrm{I}-5,6-\mathrm{IO}$ and $>$ Io drinks per week). Weight, height, waist circumference and blood pressure were measured. A history of cardiovascular disease, diabetes, hypertension and renal insufficiency in the patient and the patient's family was obtained by self-report. Medications were recorded from the patients' charts.

Each angiogram was assessed semiquantitatively by a cardiologist blinded to any experimental results. Each lesion was assessed for percent diameter stenosis rounded to the nearest I0\%. Patients with one or more lesions of more than 10\%

Table 1: Baseline characteristics of patients by outcome

\begin{tabular}{|c|c|c|c|}
\hline \multirow[b]{2}{*}{ Variable } & \multicolumn{2}{|c|}{ Patient group; mean (SD)* } & \multirow[b]{2}{*}{$p$ value } \\
\hline & $\begin{array}{c}\text { Alive } \\
n=819\end{array}$ & $\begin{array}{c}\text { Deceased } \\
n=231\end{array}$ & \\
\hline Age & $59.3(0.38)$ & $66.0(0.75)$ & $<0.001$ \\
\hline $\mathrm{TC}, \mathrm{mmol} / \mathrm{L}$ & $5.16(0.04)$ & $5.01(0.08)$ & 0.17 \\
\hline LDL-C, $\mathrm{mmol} / \mathrm{L}$ & $3.59(0.03)$ & $3.63(0.07)$ & 0.78 \\
\hline $\mathrm{HDL}-\mathrm{C}, \mathrm{mmol} / \mathrm{L}$ & $0.96(0.01)$ & $0.96(0.02)$ & 0.87 \\
\hline TC:HDL-C ratio & $5.75(0.08)$ & $5.56(0.12)$ & 0.60 \\
\hline $\begin{array}{l}\text { Triglycerides, } \mathrm{mmol} / \mathrm{L} \text {, } \\
\text { median (IQR) }\end{array}$ & $1.56(1.13-2.20)$ & $1.51(1.10-1.99)$ & 0.09 \\
\hline Apolipoprotein B, g/L & $0.97(0.01)$ & $0.96(0.02)$ & 0.55 \\
\hline Waist circumference, $\mathrm{cm}$ & $92(1)$ & $92(1)$ & 0.97 \\
\hline CRP, mg/L, median (IQR) & $1.76(0.81-4.73)$ & $3.10(1.28-6.79)$ & $<0.001$ \\
\hline $\mathrm{SAA}, \mu \mathrm{g} / \mathrm{L}$, median (IQR) & $240(96-672)$ & $398(163-1014)$ & $<0.001$ \\
\hline IL-6, ng/L, median (IQR) & $2.10(1.30-3.44)$ & $3.02(2.00-4.90)$ & $<0.001$ \\
\hline tHcy, $\mu \mathrm{mol} / \mathrm{L}$, median (IQR) & $13.6(10.8-16.7)$ & $16.2(12.6-20.9)$ & $<0.001$ \\
\hline \multicolumn{4}{|l|}{ Categorical variables, no. (\%)† } \\
\hline Women & $213(75)$ & $72(25)$ & 0.047 \\
\hline Men & $606(80)$ & $148(20)$ & \\
\hline Has never smoked & $244(83)$ & $51(18)$ & 0.044 \\
\hline Has smoked or does smoke & $556(77)$ & $166(23)$ & \\
\hline No diabetes & $694(80)$ & $173(20)$ & 0.031 \\
\hline Diabetes & $125(73)$ & $47(27)$ & \\
\hline No hypertension & $472(80)$ & $120(20)$ & 0.58 \\
\hline Hypertension & $306(78)$ & $85(22)$ & \\
\hline \multicolumn{4}{|l|}{ Alcohol consumption } \\
\hline Never & $214(78)$ & $62(22)$ & 0.62 \\
\hline 1-5 drinks/wk & $430(80)$ & $106(20)$ & \\
\hline 6-10 drinks/wk & $134(77)$ & $40(23)$ & \\
\hline$>10$ drinks/wk & $22(73)$ & $8(27)$ & \\
\hline
\end{tabular}

Note: $\mathrm{SD}=$ standard deviation, $\mathrm{TC}=$ total cholesterol, $\mathrm{LDL}-\mathrm{C}=$ low-density lipoprotein cholesterol, $\mathrm{HDL}-\mathrm{C}=$ high-density lipoprotein cholesterol, IQR = interquartile range, $\mathrm{CRP}=\mathrm{C}$-reactive protein, SAA = serum amyloid $\mathrm{A}$ protein, tHcy = total homocysteine.

*Unless stated otherwise.

†Percentages are based on row totals. stenosis were considered to be positive for $\mathrm{CAD}$, and patients with lesions of $10 \%$ or less stenosis were considered negative for CAD. This definition differs from that typically found in the literature, and it was chosen because there is increasing evidence that small plaques may contribute more than large plaques to cardiovascular morbidity and death..$^{18}$ In addition, by considering patients with any degree of narrowing to have $\mathrm{CAD}$, we hoped to be able to avoid misclassifying patients as a result of subjective differences in diagnosis around the 50\% mark. The original data collection did not permit the calculation of an angiography score.

Before the angiography procedure, fasting blood samples were collected in EDTA (ethylenediamine tetra-acetate) and centrifuged, and the plasma was divided into aliquots and stored at $-70^{\circ} \mathrm{C}$. Lipid and lipoprotein levels were measured soon after the subjects were recruited. Total cholesterol,${ }^{19}$ triglyceride, ${ }^{20}$ high-density lipoprotein cholesterol ${ }^{21}$ and apolipoprotein $\mathrm{B}^{22}$ and $\mathrm{A}-\mathrm{I}^{22}$ levels were measured using previously described methods. Low-density lipoprotein cholesterol levels were calculated using the Friedewald formula ${ }^{23}$ for patients whose plasma triglyceride level was less than $4 \mathrm{mmol} / \mathrm{L}$.

In 2002 or later the frozen plasma samples were thawed and used to quantify the levels of CRP, SAA, IL- 6 and tHcy. CRP was measured using a high-sensitivity CRP chemiluminescent enzymelabelled immunometric assay using the IMMULITE 2000 automated analyzer (Diagnostic Products Corporation, Los Angeles, Calif.). The linear range of the assay is $0.2-150 \mathrm{mg} / \mathrm{L}$, with a maximum interassay coefficient of variation (CV) of $8.7 \%$. IL- 6 was measured using the Quantikine High Sensitivity Human IL-6 Immunoassay (R\&D Systems, Minneapolis, Minn.). The assay used the quantitative sandwich enzyme immunoassay technique with a linear range of O.I-IO ng/L and a maximum interassay $\mathrm{CV}$ of $9.6 \%$. SAA was measured using a high-sensitivity Human Serum Amyloid A ELISA kit (Antigenix America Inc., Huntingdon Station, NY). The linear range of the assay is $\mathrm{I}-80 \mu \mathrm{g} / \mathrm{L}$ with a maximum interassay $\mathrm{CV}$ of $9 \%$. tHcy was measured using the ADVIA Centaur HCY assay, which uses a competitive immunoassay and direct chemiluminescent technology. The linear range of the assay is $0.5-65 \mu \mathrm{mol} / \mathrm{L}$ with a maximum interassay CV of $7.6 \%$. When necessary, plasma samples were diluted to obtain measurements in the linear range.

In July 2004, the names of the patients were linked with the British Columbia Vital Statistics database to determine 
Table 2: Hazard ratios* (HRs) for all-cause death according to quartiles of interleukin (IL)-6, serum amyloid A protein (SAA), C-reactive protein (CRP) and total homocysteine (tHcy) levels

\begin{tabular}{|c|c|c|c|c|c|}
\hline \multirow[b]{2}{*}{ Biomarker } & \multicolumn{4}{|c|}{ Quartile } & \multirow{2}{*}{$\begin{array}{l}p \text { value for } \\
\text { trend } \dagger\end{array}$} \\
\hline & 1 & 2 & 3 & 4 & \\
\hline \multicolumn{6}{|l|}{ IL-6 } \\
\hline Median, ng/L & 0.99 & 1.81 & 2.85 & 5.63 & \\
\hline Quartile range, ng/L & $\leq 1.37$ & $1.37-2.27$ & $2.27-3.77$ & $\geq 3.77$ & \\
\hline $\mathrm{HR}(95 \% \mathrm{Cl})$ & 1 & $1.60(0.98-2.64)$ & $1.40(0.85-2.30)$ & $2.57(1.62-4.09)$ & 0.001 \\
\hline \multicolumn{6}{|l|}{ SAA } \\
\hline Median, $\mu \mathrm{g} / \mathrm{L}$ & 60 & 171 & 424 & 1773 & \\
\hline Quartile range, $\mu \mathrm{g} / \mathrm{L}$ & $\leq 104$ & $104-271$ & $271-743$ & $\geq 743$ & \\
\hline $\mathrm{HR}(95 \% \mathrm{Cl})$ & 1 & $1.40(0.88-2.25)$ & $2.01(1.28-3.15)$ & $2.01(1.28-3.16)$ & 0.001 \\
\hline \multicolumn{6}{|l|}{ CRP } \\
\hline Median, mg/L & 0.51 & 1.27 & 3.13 & 10.15 & \\
\hline Quartile range, $\mathrm{mg} / \mathrm{L}$ & $\leq 0.88$ & $0.88-1.97$ & $1.97-5.16$ & $\geq 5.16$ & \\
\hline $\mathrm{HR}(95 \% \mathrm{Cl})$ & 1 & $1.32(0.83-2.09)$ & $1.70(1.08-2.66)$ & $2.12(1.38-3.27)$ & 0.003 \\
\hline \multicolumn{6}{|l|}{ tHcy } \\
\hline Median, $\mu \mathrm{mol} / \mathrm{L}$ & 9.6 & 12.6 & 15.4 & 21.4 & \\
\hline Quartile range, $\mu \mathrm{mol} / \mathrm{L}$ & $\leq 11.1$ & $11.1-14.1$ & $14.1-17.4$ & $\geq 17.4$ & \\
\hline $\mathrm{HR}(95 \% \mathrm{Cl})$ & 1 & $1.29(0.80-2.08)$ & $1.64(1.04-2.61)$ & $2.36(1.53-3.65)$ & $<0.001$ \\
\hline
\end{tabular}

Note: $\mathrm{Cl}=$ confidence interval.

*Adjusted for age, sex, total cholesterol:high-density lipoprotein cholesterol ratio, triglyceride and apolipoprotein B levels, waist

circumference, diabetes, smoking status and hypertension.

†Quartiles were treated as a continuous variable to test if the regression coefficient is significantly different from zero.

whether they had died. Deaths occurring outside of the province of British Columbia were not identified or included in the analysis. CAD-related death was considered to have occurred when the underlying cause of death was attributed to ischemic heart disease according to the International Classification of Disease, Ioth revision (ICD-Io-CM codes I2O-I25). ${ }^{24}$

Univariate analyses of continuous variables were carried out using the Mann-Whitney test for independent samples, and the $\chi^{2}$ test was used to evaluate categorical variables. To assess the relation of IL-6, CRP, SAA and tHcy levels with death, Cox regression analyses were performed across quartiles where the first quartile was used as the reference category. To test for the presence of a trend across categories, quartiles were treated as a continuous variable in the Cox regression model. Comparison of area under the curve or receiver operating characteristic plots was performed using previously described methods. ${ }^{25}$ To determine the strongest independent risk factors for $\mathrm{CAD}$, multivariate logistic regression analyses were performed with age, sex, total cholesterol:high-density lipoprotein cholesterol (TC:HDL-C) ratio, triglyceride and apolipoprotein B levels, diabetes, waist circumference, hypertension, smoking status (ever or current), and CRP, SAA, IL-6 and tHcy levels included as covariates using a forward stepwise method. The end-point of survival analyses was all-cause death or death related to cardiovascular causes. The association of plasma biomarkers with outcome was evaluated by a Cox regression analysis adjusted for the same covariates mentioned above in addition to angiographic $\mathrm{CAD}$ using a forward stepwise method. The Kaplan-Meier test with log-rank statistics was used to evaluate differences in survival for increasing numbers of elevated plasma biomarkers.

\section{Results}

Of III7 subjects recruited, angiography results were available for IoI9. Data obtained from the British Columbia Vital Statistics database in July 2004 indicated that 23I patients (22\%) had died, of whom 95 ( $9 \%$ had died of CAD-related causes. The mean follow-up time was 8.5 years.

Many of the traditional risk factors for $\mathrm{CAD}$, such as age, waist circumference, TC:HDL-C ratio and triglyceride and apolipoprotein $\mathrm{B}$ levels, were significantly higher in the $\mathrm{CAD}$ group than in the CAD-negative group, whereas HDL-C levels were significantly lower in the CAD group (Appendix I, available at www.cmaj.ca/cgi/content/full/050880/DCI). Also, in categorical analyses, the proportions of men, patients who smoked and patients with diabetes were higher in the CAD group ( $p<0.00$ I for all 3 variables) (Appendix I). By contrast, CRP, SAA and IL-6 levels were not significantly different between the 2 groups, although higher levels were observed in the $\mathrm{CAD}$ group for each inflammatory marker. Comparison of tHcy levels indicated that significantly higher levels were observed in the CAD group ( $p=0.010$ ). If CAD was defined as having one or more lesions with greater than $50 \%$ stenosis and the reference group was patients with lesions of $50 \%$ or 
less stenosis, statistical relations were similar to those reported in Appendix I with the exception that CRP and IL-6 levels were significantly higher in the CAD group $(p=0.029$ and $p=0.004$, respectively).

Comparison of alive and deceased groups indicated that baseline levels of CRP, IL-6, SAA and tHcy were elevated in the deceased group ( $p<0.00 \mathrm{I}$ in all cases) (Table I). No other plasma biomarker measured was associated with allcause death. There was a higher proportion of women than of men in the deceased group ( $25 \% \mathrm{v} .20 \%, p=0.047$ ). Also, the frequency of smoking and diabetes was higher in the deceased group ( $p=0.044$ and $0.03 \mathrm{I}$, respectively) (Table I). Patients who died of cardiovascular causes had higher levels of CRP, SAA, IL- 6 and tHcy than those who were still alive $(p=0.00 \mathrm{I}, p=0.003, p<0.00 \mathrm{I}$ and $p<0.00 \mathrm{I}$, respectively). No other plasma biomarkers or risk factors were significantly different between these 2 groups (data not shown).

After adjustment for age, sex, TC:HDL-C ratio, triglyceride and apolipoprotein B levels, waist circumference, diabetes, smoking status and hypertension, patients in the highest quartiles for IL-6, SAA, CRP and tHcy levels had a significantly increased risk of death (by a factor of 2.0I-2.57) compared with those in the lowest quartile with significant trends across quartiles (Table 2). Further adjustments for use of lipid-lowering medication ( $17 \%$ frequency) and a self-report

Table 3: Odds ratios (ORs) for presence of coronary artery disease $(C A D),{ }^{*}$ CAD-related death and all-cause death

\begin{tabular}{lcc}
\hline Variable & Adjusted OR† $(95 \% \mathrm{Cl})$ & $p$ value \\
\hline Presence of CAD & & \\
\hline Age & $1.05(1.03-1.07)$ & $<0.001$ \\
\hline Sex & $5.40(3.63-8.02)$ & $<0.001$ \\
\hline Smoking status & $2.03(1.38-2.96)$ & 0.003 \\
Diabetes & $2.74(1.46-5.15)$ & 0.002 \\
\hline Apolipoprotein B & $1.36(1.17-1.59)$ & 0.001 \\
\hline CAD-related death & & \\
\hline Age & $1.07(1.05-1.10)$ & $<0.001$ \\
\hline Angiographic CAD & $3.52(1.42-8.74)$ & 0.007 \\
\hline IL-6 & $1.08(1.01-1.16)$ & 0.03 \\
\hline tHcy & $1.05(1.02-1.08)$ & 0.002 \\
\hline All-cause death & & \\
\hline Age & $1.05(1.03-1.07)$ & $<0.001$ \\
\hline Diabetes & $1.53(1.07-2.18)$ & 0.02 \\
\hline IL-6 & $1.08(1.04-1.13)$ & 0.004 \\
\hline tHcy & $1.05(1.03-1.07)$ & $<0.001$ \\
\hline
\end{tabular}

Note: $\mathrm{Cl}=$ confidence interval, IL-6 = interleukin- 6 , tHcy = total homocysteine.

*Presence of CAD was defined as $\geq 1$ lesions of $>10 \%$ stenosis; patients with lesions of $\leq 10 \%$ stenosis were considered negative for CAD.

tCovariates evaluated included age, sex, total cholesterol:high-density lipoprotein cholesterol ratio, triglyceride levels, apolipoprotein B levels $(0.2 \mathrm{~g} / \mathrm{L}$ increment), waist circumference $(5 \mathrm{~cm}$ increment $)$, diabetes, hypertension, smoking (ever or current), and C-reactive protein, serum amyloid A protein, IL-6 and tHcy levels. Angiographic CAD was included as a covariate for analyses of predictor variables for all-cause and CAD-related death. of renal insufficiency ( $3 \%$ frequency) did not substantially change this observation (data not shown).

Appendices 2-4, available at www.cmaj.ca/cgi/content /full/050880/DCI, show the comparison of the area under the curve obtained for receiver operating characteristic curves plotted for all of the plasma biomarkers measured, including TC:HDL-C ratio, for their ability to predict death by any cause. Elevated levels of CRP, SAA, IL-6 and tHcy were better predictors of death by any cause than chance, whereas the receiver operating characteristic curves for lipid and apolipoprotein B levels were not significant. The area under the curve was greatest for IL- 6 followed by tHcy, SAA, and CRP. The area under the curve for IL- 6 was significantly greater than those observed for SAA and CRP. Receiver operating characteristic curve analysis for CAD-related death yielded similar results, where the largest area under the curve was observed for IL- 6 and was significantly greater than that for CRP.

Age, male sex, diabetes and smoking status were independent predictors of CAD in a forward stepwise logistic regression model (Table 3). Apolipoprotein B was the only plasma biomarker that was an independent predictor of CAD, with an odds ratio of I.36 (95\% CI I.I7-I.59) for each increment of $0.2 \mathrm{~g} / \mathrm{L}$. A Cox regression model containing the same variables mentioned above as well as angiographic $\mathrm{CAD}$ indicated that age, angiographic CAD, and elevated IL- 6 and tHcy levels were the strongest independent predictors of CAD-related death, whereas age, diabetes, and elevated IL- 6 and tHcy levels were the strongest predictors of all-cause death. Hazard ratios of $\mathrm{I} .08$ (95\% CI I.OI-I.I6, $p=0.03$ ) or an $8 \%$ increase in CAD-related death for each ng/L increase in IL-6 and I.05 (95\% CI I.02-I.08, $p=0.002$ ) or $5 \%$ increase in CAD-related death for each $\mu \mathrm{mol} / \mathrm{L}$ increase in tHcy were observed for CAD-related death (Table 3).

Survival analysis was performed to determine whether elevated levels of multiple biomarkers in the fourth quartile were associated with decreased survival (Fig. I). A significant trend was observed when comparisons were made between the presence of o, I, 2, 3 and 4 elevated levels of biomarkers for all-cause and CAD-related death ( $p<0.00 \mathrm{I}$ in each case).

\section{Interpretation}

We analyzed the relative and combined utility of CRP, SAA, IL- 6 and tHcy as predictors of angiographic CAD and death. In the study population, traditional CAD risk factors such as age, male sex, smoking status and diabetes were independent predictors of CAD. The only plasma biomarker indicative of CAD was apolipoprotein $\mathrm{B}$. However, of all risk factors, angiographic CAD and elevated levels of IL- 6 and tHcy emerged as the strongest independent predictors of CADrelated death. Survival analysis indicated the capacity to predict either all-cause or CAD-related death increased when elevated measures of CRP, SAA, IL- 6 and tHcy were combined.

High apolipoprotein B levels and traditional CAD risk factors such as diabetes and smoking have recently been recognized as common among the global community. ${ }^{26}$ In this 
A

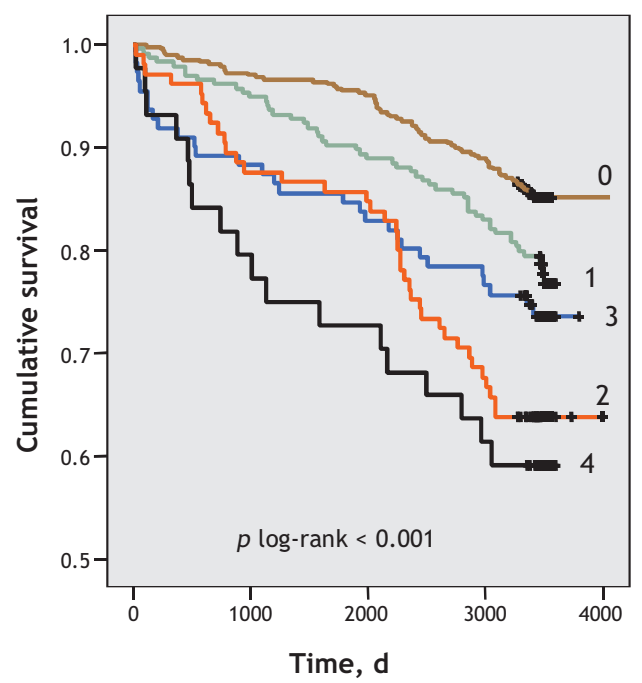

B

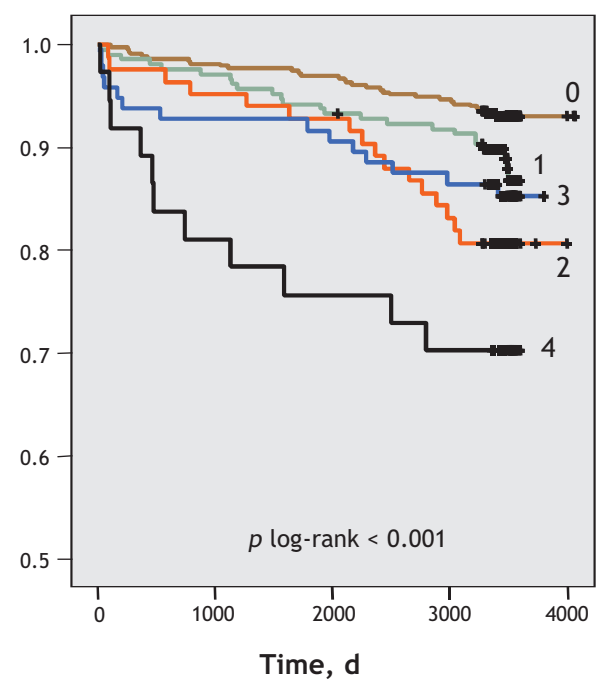

Fig. 1: Kaplan-Meier curves for all-cause and CAD-related death according to the number of plasma biomarkers (interleukin- 6 , serum amyloid A protein, C-reactive protein and total homocysteine) in the fourth quartile. A: The number of all-cause deaths per total number of patients in each category are as follows: o biomarkers, $69 / 471 ; 1,51 / 235 ; 2,38 / 105 ; 3,29 / 111 ; 4,18 / 44$. B: The number of CAD-related deaths per total number of patients in each category are as follows: o biomarkers, 30/471; 1, 24/235; 2, 16/105; 3, 14/111; 4, 11/44.

study, none of CRP, SAA, IL- 6 or tHcy was found to be an independent predictor of angiographic $\mathrm{CAD}$. The observed relation between these 4 biomarkers and angiographic CAD is typically not strong, particularly in multivariate analyses, where either modest or no associations have been reported. ${ }^{9,27-31}$ These data suggest that elevated apolipoprotein $\mathrm{B}$ levels are superior to those of CRP, SAA, IL- 6 or tHcy in predicting the presence of atherosclerotic lesions.

These data indicate that IL- 6 and tHcy have independent effects and are better predictors of CAD-related death than other inflammatory or lipid biomarkers. Consistent with this observation are previous reports of an elevated IL-6 level as an independent marker of increased risk of death and cardiovascular events in a variety of patient cohorts. ${ }^{32-34}$ Furthermore, the results of previous studies have indicated that elevated IL6 levels have stronger predictive value than elevated CRP levels for CAD-related death ${ }^{35}$ and cardiovascular events. ${ }^{36}$ Similarly, elevated tHcy levels have been shown to be a predictor of all-cause and CAD-related death, ${ }^{10,11,37}$ and in 2 studies, this relation was independent of traditional risk factors and CRP. ${ }^{38,39}$ However, elevated levels of CRP but not of tHCy or lipids were associated with sudden cardiac death in a I7-year follow-up of apparently healthy men. ${ }^{40}$ The difference in results may be because the causes of sudden cardiac death are different from those of all-cause or CAD-related death.

Comparisons of survival between those subjects who had o, I, 2, 3 or 4 elevated markers among CRP, SAA, IL-6 and tHcy revealed an increasing rate of death and CAD-related death. As such, there appears to be increased prognostic value when measures of all 4 biomarkers are combined. A cumulative risk of 5 different inflammatory markers for coronary events was also recently reported in a cohort of 6075 apparently healthy men followed prospectively with a mean follow-up of I9 years.$^{41}$ However, in our study, it appears that these biomarkers may not be specific for CAD, since elevated IL-6 and tHcy levels were predictive of death by any cause.

There are several limitations to this study. First, it is important to note that the analyses described for this study cohort are based on the measurement of plasma biomarkers at a single point in time. We did not evaluate whether the levels of these markers changed with time or were influenced by medications after the angiography or by additional genetic and environmental factors. Angiography assesses only those lesions that protrude into the lumen and does not indicate CAD within outwardly modelled vessels. Furthermore, we did not measure other recognized indicators of inflammation such as elevated leukocyte counts and the erythrocyte sedimentation rate. Also, the lack of a measure of renal function prevented us from assessing the influence of this variable on biomarker levels and outcomes. Last, the relation of biomarker levels with outcomes was observed in patients referred for angiography and may not be directly applicable to the general population.

Although the results of this study indicate that the baseline measurement of IL- 6 and tHcy as individual markers has greater utility in predicting death than traditional lipid and apolipoprotein measurements, IL- 6 and tHcy do not appear to be specific predictors for CAD-related death. By contrast, greater prognostic value is achieved when IL- 6 and tHcy are included as part of a group of biomarkers that together increase our ability to identify those subjects with greatest risk of death. 


\section{Editor's take}

- Although, along with age and diabetes, anatomic severity of coronary artery disease is a strong predictor of subsequent death, a number of other plasma markers may be helpful in predicting death, particularly among patients who have undergone coronary angiography.

- In this study of over 1000 patients who had coronary angiograms and were followed for an average of 8.5 years, substantial increases in risk of death were associated with increasing levels of plasma C-reactive protein, interleukin (IL)6 , serum amyloid A protein and total homocysteine (tHcy).

Implications for practice: In the presence of known coronary artery disease, plasma biomarkers, in particular IL-6 and tHcy, are the strongest independent markers of subsequent CADrelated death.

This article has been peer reviewed.

All of the authors are from the James Hogg iCAPTURE Centre of Cardiovascular and Pulmonary Research and, except for Keith Walley, the Healthy Heart Program, St. Paul's Hospital, Department of Pathology and Laboratory Medicine, and the University of British Columbia, Vancouver, B.C.

Competing interests: None declared.

Contributors: All of the authors contributed equally to the drafting and critical revision of the manuscript, gathered the information presented and approved the final version for publication.

Acknowledgements: This study was supported by a grant from the Heart and Stroke Foundation of British Columbia and Yukon. John Hill is a scholar of the Michael Smith Foundation for Health Research. Keith Walley is a Distinguished Scholar of the Michael Smith Foundation for Health Research.

\section{REFERENCES}

I. Ridker PM. Clinical application of C-reactive protein for cardiovascular disease detection and prevention. Circulation 2003;107:363-9.

2. Yeh ETH, Willerson JT. Coming of age of C-reactive protein: using inflammation markers in cardiology. Circulation 2003;107:370-I.

3. Danesh J, Wheeler JG, Hirschfield GM, et al. C-reactive protein and other circulating markers of inflammation in the prediction of coronary heart disease. $\mathrm{N} \mathrm{Engl} \mathrm{J}$ Med 2004;350:1387-97.

4. Bermudez EA, Rifai N, Buring J, et al. Interrelationships among circulating interleukin-6, C-reactive protein, and traditional cardiovascular risk factors in women. Arterioscler Thromb Vasc Biol 2002;22:1668-73.

5. Morrow DA, Rifai N, Antman EM, et al. Serum amyloid A predicts early mortality in acute coronary syndromes: A TIMI IIA substudy. J Am Coll Cardiol 2000;35:358-62.

6. Liuzzo G, Biasucci LM, Gallimore JR, et al. The prognostic value of C-reactive protein and serum amyloid A protein in severe unstable angina. NEngl JMed I994;33I:4I7-24.

7. Ridker PM, Rifai N, Pfeffer MA, et al. Inflammation, pravastatin, and the risk of coronary events after myocardial infarction in patients with average cholesterol levels. Cholesterol and Recurrent Events (CARE) Investigators. Circulation 1998;98:839-44.

8. Fyfe AI, Rothenberg LS, DeBeer FC, et al. Association between serum amyloid A proteins and coronary artery disease: evidence from two distinct arteriosclerotic processes. Circulation 1997;96:2914-9.

9. Johnson BD, Kip KE, Marroquin OC, et al. Serum amyloid A as a predictor of coronary artery disease and cardiovascular outcome in women: the National Heart, Lung, and Blood Institute-Sponsored Women's Ischemia Syndrome Evaluation (WISE). Circulation 2004;I09:726-32.

Io. Bostom AG, Silbershatz H, Rosenberg IH, et al. Nonfasting plasma total homocysteine levels and all-cause and cardiovascular disease mortality in elderly Framingham men and women. Arch Intern Med I999;159:1077-80.

II. Nygard O, Nordrehaug JE, Refsum H, et al. Plasma homocysteine levels and mortality in patients with coronary artery disease. N Engl J Med 1997;337:230-6

I2. Wald DS, Law M, Morris JK. Homocysteine and cardiovascular disease: evidence on causality from a meta-analysis. BMJ 2002;325:1202.
13. Homocysteine Studies Collaborations C. Homocysteine and risk of ischemic heart disease and stroke: a meta-analysis. JAMA 2002;288:2015-22.

I4. Tracy RP. Inflammation in cardiovascular disease: cart, horse or both - revisited. Arterioscler Thromb Vasc Biol 2002;22:1514-5.

15. Francis MC, Frohlich JJ. Coronary artery disease in patients at low risk: apolipoprotein $\mathrm{AI}$ as an independent risk factor. Atherosclerosis 2001;155:165-70.

I6. Lee KWJ, Ayyobi AF, Frohlich JJ, et al. APOA5 gene polymorphism modulates levels of triglyceride, HDL cholesterol and FERHDL but is not a risk factor for coronary artery disease. Atherosclerosis 2004;176:165-72.

I7. Frohlich J, Dobiasova M. Fractional esterification rate of cholesterol and ratio of triglycerides to HDL-cholesterol are powerful predictors of positive findings on coronary angiography. Clin Chem 2003;49:1873-80.

I8. Haft JI, Haik BJ, Goldstein JE, et al. Development of significant coronary artery lesions in areas of minimal disease. A common mechanism for coronary disease progression. Chest I988;94:73I-6.

I9. Kattermann R, Jaworek D, Moller G, et al. Multicentre study of a new enzymatic method of cholesterol determination. J Clin Chem Clin Biochem I984;22:245-5I.

20. Nagele U, Hagele EO, Sauer G, et al. Reagent for the enzymatic determination of serum total triglycerides with improved lipolytic efficiency. J Clin Chem Clin Biochem I984;22:165-74.

2I. Burstein M, Scholnick HR, Morfin R. Rapid method for the isolation of lipoproteins from human serum by precipitation with polyanions. J Lipid Res I970;II:583-95.

22. Sternberg JC. A rate nephelometer for measuring specific proteins by immunoprecipitin reactions. Clin Chem I977;23:1456-64.

23. Friedewald WT, Levy RI, Fredrickson DS. Estimation of the concentration of lowdensity lipoprotein cholesterol in plasma, without use of the preparative ultracentrifuge. Clin Chem 1972;18:499-502.

24. World Health Organization. International statistical classification of diseases and related health problems. Ioth rev. Geneva: The Organization; I992.

25. Hanley JA, McNeil BJ. A method of comparing the areas under receiver operating characteristic curves derived from the same cases. Radiology ig83;I48:839-43.

26. Yusuf S, Hawken S, Ounpuu S, et al. Effect of potentially modifiable risk factors associated with myocardial infarction in 52 countries (the INTERHEART study): case-control study. Lancet 2004;364:937-52.

27. Rifai N, Joubran R, Yu H, et al. Inflammatory markers in men with angiographically documented coronary heart disease. Clin Chem 1999;45:1967-73.

28. Brilakis ES, McConnell JP, Ballman KV, et al. Lack of association between plasma homocysteine and angiographic coronary artery disease in the era of fortification of cereal grain flour with folic acid. Atherosclerosis 2002; $165: 375-8 \mathrm{I}$.

29. Haverkate F, Thompson SG, Pyke SD, et al. Production of C-reactive protein and risk of coronary events in stable and unstable angina. European Concerted Action on Thrombosis and Disabilities Angina Pectoris Study Group. Lancet I997;349:462-6.

30. Erren M, Reinecke H, Junker R, et al. Systemic inflammatory parameters in patients with atherosclerosis of the coronary and peripheral arteries. Arterioscler Thromb Vasc Biol I999;19:2355-63.

3I. Zebrack JS, Muhlestein JB, Horne BD, et al. Intermountain Heart Collaboration Study G. C-reactive protein and angiographic coronary artery disease: independent and additive predictors of risk in subjects with angina. J Am Coll Cardiol 2002;39:632-7.

32. Harris TB, Ferrucci L, Tracy RP, et al. Associations of elevated interleukin-6 and Creactive protein levels with mortality in the elderly. Am J Med I999;I06:506-I2.

33. Ridker PM, Rifai N, Stampfer MJ, et al. Plasma concentration of interleukin-6 and the risk of future myocardial infarction among apparently healthy men. Circulation 2000;IOI:I767-72.

34. Lindmark E, Diderholm E, Wallentin L, et al. Relationship between interleukin 6 and mortality in patients with unstable coronary artery disease: effects of an early invasive or noninvasive strategy. JAMA 2001;286:2107-13.

35. Panichi V, Maggiore U, Taccola D, et al. Interleukin- 6 is a stronger predictor of total and cardiovascular mortality than C-reactive protein in haemodialysis patients. Nephrol Dial Transplan. 2004;19:1154-6o.

36. Cesari $\mathrm{M}$, Penninx $\mathrm{BWJH}$, Newman $\mathrm{AB}$, et al. Inflammatory markers and onset of cardiovascular events: results from the Health ABC study. Circulation 2003; I08: 2317-22.

37. Vollset SE, Refsum H, Tverdal A, et al. Plasma total homocysteine and cardiovascular and noncardiovascular mortality: the Hordaland Homocysteine Study. Am J Clin Nutr 2001;74:130-6.

38. Shai I, Stampfer MJ, Ma J, et al. Homocysteine as a risk factor for coronary heart diseases and its association with inflammatory biomarkers, lipids and dietary factors. Atherosclerosis 2004; $177: 375-8 \mathrm{I}$.

39. Anderson JL, Muhlestein JB, Horne BD, et al. Plasma homocysteine predicts mortality independently of traditional risk factors and C-reactive protein in patients with angiographically defined coronary artery disease. Circulation 2000;102:1227-32.

40. Albert CM, Ma J, Rifai N, et al. Prospective study of C-reactive protein, homocysteine, and plasma lipid levels as predictors of sudden cardiac death. Circulation 2002;105:2595-9.

4I. Engstrom G, Hedblad B, Stavenow L, et al. Fatality of future coronary events is related to inflammation-sensitive plasma proteins: a population-based prospective cohort study. Circulation 2004;110:27-31.

Correspondence to: Dr. John S. Hill, St. Paul's Hospital, Healthy Heart Program, I08I Burrard St., Vancouver BC V6Z IY6; fax 604 8o6-859o; jshill@interchange.ubc.ca 